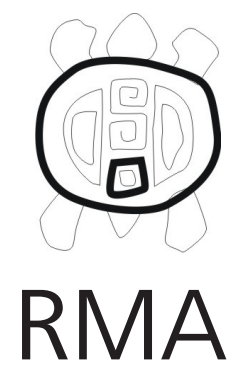

Dossier

\section{El movimiento institucionalizado: danzas folklóricas argentinas, la profesionalización de su enseñanza}

María Belén Hirose

IDES - FONCYT. PICT 2006-1728 Antropología social e histórica del campo antropológico en la Argentina, 1940-1980. E-mail: belenhirose@gmail.com

\begin{abstract}
Resumen
En 1948 se creó la Escuela Nacional de Danzas Folklóricas, como parte del Plan Quinquenal del primer gobierno de Juan D. Perón (1946-1952). Así se dio inicio a la profesionalización de la transmisión y difusión de las danzas folklóricas en su carácter de danzas nacionales, tarea que quedaría concretada con la formación de un cuerpo de profesores nacionales de danza. Este proceso suponía el establecimiento de criterios de selección y transformación de aquellas danzas que se consideraran adecuadas para dar materialidad, mediante coreografías, música, vestimenta y eventos, al sentimiento de la nacionalidad. El folklore académico, en pleno proceso de consolidación como disciplina científica, fue también funcional al proyecto nacional, proveyendo los criterios para la creación del repertorio de danzas que sería enseñado en Buenos Aires y transportado luego a las provincias.

En este artículo nos proponemos describir el desarrollo histórico que posibilitó la institucionalización de la enseñanza de las danzas folklóricas en la Argentina, y los efectos de dicha institucionalización. Exploramos el rol que diversos grupos o individuos pertenecientes al ámbito político, cultural y/o académico, asignaron a la enseñanza de las danzas folklóricas en las diferentes etapas del proceso de construcción y fortalecimiento del estado-nación argentino.
\end{abstract}

Palabras clave: danza; folklore; Argentina; docencia; peronismo

Institutionalized movement: professional education of argentine folk dances

\begin{abstract}
In 1948 Argentina's National School of Folkloric Dances was created as a part of Juan D. Peron's "Quinquennial Plan", launched during his first administration. Thus, the transmission and diffusion of folkloric dances as national symbols began to be professionalized, the development of which was accomplish by the instruction of a troupe of national dance teachers. This process required a repertoire based on the selection and transformation of those dances considered to be adequate expressions of Argentine nationhood, by means of choreography, music, clothing and events. Folklore, consolidating by the time as a scientific discipline, was functional to the national project, giving the criteria for the creation of a dance repertoire taught in Buenos Aires and expanded to the whole country. In this article we will describe the historical development that enables folkloric dances teaching institutionalization in Argentina, as well as the effects of such institutionalization. We will explore the rol that different groups or individuals from the political, cultural or academic realm attributed to the teaching of folkloric dances, during the process of nation-state building.
\end{abstract}

Keywords: dance; folklore; Argentina; teaching; Peronism

\section{La creación de la Escuela Nacional de Danzas Folklóricas}

Los Estados Nacionales han recurrido históricamente a diversas actividades expresivas (literatura, teatro, música, danza) como procesos para vehiculizar los sentimientos de pertenencia nacional. En su reseña de investigaciones sobre danzas, Reed (1998) confirma que la apropiación de las prácticas de la cultura campesina o de las clases bajas urbanas por el Estado es una estrategia extendida en el desarrollo de culturas nacionales en todo el mundo, ya sea como indicadores de la dominación de un grupo étnico o como despliegue de pluralismo cultural (1998:
511). Meyer (1995), por su parte, concluye que el recurso a la actividad dancística por parte de los estados nación resulta más vigoroso que la retórica política o los debates intelectuales para suscitar adhesiones individuales (en Reed 1998:511). Por ello, una diversidad de estudios de caso se construyen a partir de la hipótesis de que la danza es un elemento eficaz para dar cuerpo a las ideologías nacionales a través de la creación de sujetos nacionales (Archetti 2003; Feldman 2006; Guss 2000; Hughes-Freeland 2006; Kaeppler 2006; Manners 2006; Martinez 2002; Mendoza 2008; O'Shea 2006; Wulf 2003). No es sorprendente, entonces, encontrar muchas investigaciones sobre danza en las cuales se documenta 
cómo los estados nacionales procedieron a la apropiación - selección y transformación mediantes - de algunas danzas para clasificarlas como folklóricas y mediante este proceso destacar su carácter nacional. A continuación, nos concentraremos en las particularidades del caso argentino, en cómo algunos bailes pasaron a formar parte del abanico de actividades propicios para ser practicados o espectados como índices de identidad nacional, cuándo comenzó este proceso y cómo se institucionalizó en la enseñanza de nivel superior.

En 1948, durante el primer gobierno del General Domingo Perón, y en el marco del plan Quinquenal, se crea la Escuela Nacional de Danzas Folklóricas Argentinas, por Decreto Nacional N²7.860. El proyecto fue ideado por Antonio Barceló, maestro de danzas en ámbitos públicos (conservatorios) y privados (academias), y contó con el apoyo del poeta Leopoldo Marechal, por entonces Director General de Cultura. El texto de la ley sostenía que el estudio y la difusión de tradiciones nacionales formaban parte de los principales objetivos del gobierno nacional, lo que suponía la restitución al pueblo de los "valores intelectuales, morales y plásticos" propios del "alma nacional". A tal fin, reconocía a las danzas nativas como una "especie folklórica" particularmente importante porque expresaban "en grado eminente la circunspección y la gracia de nuestra estirpe". Se hacía indispensable entonces "conservarlas en toda su pureza de estilo y darles nueva vigencia en los medios populares de las que fueron enajenadas por influencias foráneas".

El decreto menciona como antecedente para la creación de la Escuela Nacional de Danzas, un curso de Danzas Folklóricas en el Conservatorio Nacional de Música y Arte Escénico, que se había lanzado como experiencia piloto en 1939. El curso había suscitado un gran interés en profesores, maestros, empleados, obreros y profesionales, desbordando las capacidades didácticas existentes hasta entonces. Por eso, el decreto sostenía que era indispensable que existiera un instituto donde se pudiera formar "un cuerpo de técnicos capacitados para la docencia en esta materia, con el objetivo primordial de unificar la enseñanza, resguardar la autenticidad y pureza de nuestras expresiones folklóricas, y contribuir a que conserven su estilo, dentro del más riguroso concepto estético como manifestación del sentir artístico y espiritual de nuestro pueblo." La puesta en marcha de la Escuela Nacional de Danzas Folklóricas, pues, respondía a una creciente demanda por personas que se considerasen capacitadas para la enseñanza de bailes folklóricos. Esa demanda fue atendida por el Estado nacional con la creación de una institución que unificaría los criterios de transmisión y conservación de las expresiones folklóricas valoradas por su "autenticidad" y por su capacidad de reflejar a la nación. Ahora bien: pese a la novedad, las nociones que informaban estas convicciones sobre la relación entre expresiones folklóricas y nación provenían de períodos anteriores, cristalizándose con la creación de la Escuela.

\section{Folklore y nacionalismo}

Muchos intelectuales nacionalistas - directa o indirectamente ligados a los aparatos de estado- intervienen activamente en el proceso de re-contextualización por el cual deben pasar las danzas populares para convertirse en emblemas y representaciones de la nación. La participación de estos agentes en la selección y puesta en escena de estos bailes en tanto que nacionales, responde al supuesto de que las danzas son más eficaces que los debates ideológicos para la creación de sujetos nacionales ${ }^{1}$. La disciplina académica folklore, nacida del encuentro entre una mirada romántica y la valorización del método científico, fue una fuente importante de intelectuales cuya labor fue, en muchos aspectos, funcional a la dimensión cultural en la construcción de los estados-nación.

La relación entre los estudios folklóricos y los nacionalismos (tanto en los países europeos como en los americanos), estuvo mediada por el romanticismo que buscaba en las prácticas ligadas -real o imaginariamente- al pasado, ese núcleo inmutable que definiría la esencia nacional. Oscar Chamosa (2010), estudioso del movimiento folklórico argentino, en el que incluye tanto su dimensión académica como pública ${ }^{2}$, sostiene que el nacionalismo cultural es una de las tres corrientes que confluyen para dar impulso al movimiento durante el período Radical, desde 1916. Las otras dos influencias fueron la promoción de las investigaciones folklóricas por las elites provinciales, y el trabajo de un grupo de artistas y productores que basaron sus creaciones en los géneros criollos. En su retroalimentación, los miembros del movimiento folklórico proveyeron un cúmulo de conocimientos y un lenguaje estético para los diferentes nacionalismos, siendo su mayor contribución la presentación de las formas culturales rurales como la cultura auténtica nacional, justo cuando la Argentina se estaba convirtiendo en un país urbano, cosmopolita y exportador central de los productos templados de la Pampa húmeda al mercado mundial (2010: 2-3):

Los principales protagonistas del movimiento folklórico se inspiraron en el discurso nacionalista, especialmente de autores tempranos como Joaquín V. González y Ricardo Rojas. Sobretodo, con la acumulación de una masa de conocimiento sobre la cultura criolla local y la creación de un género que podía ser adaptado tanto a la educación como al entretenimiento, los investigadores del folklore y los artistas folklóricos establecieron un lenguaje estético visual, auditivo y coreográfico para el

\footnotetext{
${ }^{1}$ Supuesto que opera en el discurso estatal, pero que no es automáticamente asumido por los bailarines.

2 Por folklore académico entiende al grupo de "científicos" encargados de armar un archivo de formas de folklore canónico, por folklore público entiende los festivales, conmemoraciones y museos en los que intervienen tanto agencias gubernamentales, asociaciones privadas / comunales, artistas y empresarios culturales.
} 
nacionalismo (Chamosa 2010: 7, nuestra traducción). ${ }^{3}$ Ricardo Rojas (1882-1957) 4 fue el primero en sugerir la enseñanza de la geografía, la historia y el folklore criollo - sus canciones, danzas, proverbios, etc. - para actuar sobre las emociones internas de los niños y forjar cinestésicamente una memoria colectiva, ya que la identidad nacional surgiría de un conocimiento compartido de estos elementos, lo que favorecería la integración de todos los habitantes en una misma nación (Chamosa 2010:40-41). Ya en su obra Cosmópolis (1908), Rojas sostenía que la recopilación de datos de la cultura popular era fundamental para la constitución del nacionalismo (antimercantilista), aunque por entonces no apelaba a la intervención del estado para realizar esa tarea (Degiovanni 121-122). Es en La Restauración Nacionalista donde aparece cristalizada la necesidad de enseñar el folklore - bailes, cantos, proverbios, leyendas y cuentos - en las escuelas como medio para reconocer-se en el colectivo nacional:

El folclor tiene además una importancia política: él define la persistencia del alma nacional, mostrando cómo, á pesar del progreso y de los cambios externos, hay en la vida de las naciones una substancia intrahistórica que persiste. Esa substancia intra histórica es la que hay que salvar, para que un pueblo se reconozca siempre á si mismo. De ahí que los historiadores y los artistas deban reconstituirlo, de ahí que los maestros deban enseñarlo. Los bailes y cantos pueden aprovecharse en las clases respectivas, explicando su sentido histórico; sus proverbios en las de moral, sus instituciones consuetudinarias en las de instrucción cívica, sus vocablos arcaicos en las de gramática, su empirismo en las de ciencia, sus leyendas y cuentos, cuando hubiesen pasado á la literatura, en las lecturas auxiliares. (...). Estas aplicaciones del foclor á la enseñanza, han sido realizadas, según lo expondré en capítulos oportunos, por países como Inglaterra y Alemania. (Rojas 1909: 60-1, la negrita es nuestra)

Con respecto a la constitución del folklore académico en la Argentina, en su artículo "Folklore y nacionalismo en la Argentina: su vinculación de origen y su desvinculación actual" Martha Blache (1991) recorre las distintas etapas de los estudios folklóricos, desde los precursores hasta fines del siglo XX. Entre los precursores (Lafone Quevedo, Eric Boman, Juan B. Ambrosetti, Lehmann-Nitsche) y la

\footnotetext{
3 "The main actors in the folklore movement drew inspiration from nationalist discourse, especially early nationalist authors such as Joaquín V. González and Ricardo Rojas. Overall, by accumulating a mass of knowledge about criollo local culture and creating a genre that could be adapted to both education and entertainment, research folklorists and artists established a visual, aural, and choreographic aesthetic language for nationalism." (Chamosa 2010: 7).

4 Rojas nació en la ciudad de San Miguel de Tucumán pero provenía de una familia de renombre de Santiago del Estero. De orientación nacionalista, fue luego militante radical, además de decano de la Facultad de Filosofía y Letras de la Universidad de Buenos Aires, y rector de dicha universidad.
}

sistematización de los estudios folklóricos, Blache señala a un grupo de "amantes de la tradición pero sin los adecuados instrumentos para recogerla y analizarla" que personaliza en las familias aristocráticas de las provincias, y que significa un "pesado lastre" para la folklorística, por el "patrioterismo" (60) con que dichas exploraciones estuvieron imbricadas en sus contextos de producción ${ }^{5}$. Luego vendrían las décadas del 30 al 60, conocidos como la época de oro de las investigaciones folklóricas (Martín 2005). Personalidades como Juan Alfonso Carrizo, Alfredo Poviña, Augusto Raúl Cortazar, Carlos Vega, Félix Coluccio, etc., protagonizaron esta prolífica etapa, basada en un modelo campesino del folklore. Sin embargo, desde el punto de vista de Blache, la amplia influencia de este grupo de intelectuales se convertiría en un obstáculo para la apertura y renovación de la teoría folklórica hacia corrientes que no estuvieran enfocadas en el "espíritu del pueblo".

Cabe destacar que si bien existen muchas conexiones entre folklore y nacionalismo, existió una gran heterogeneidad de intereses y apoyos políticos entre las personas identificadas con el folklore. Los empresarios de los molinos azucareros tucumanos que apoyaron la investigación folklórica, estaban a favor del gobierno entre 1932-43, al que se oponían los nacionalistas; los empresarios de los medios de comunicación -radio y prensa- estaban más bien interesados en promocionar un producto entretenido, con una impronta nacional; otros artistas como Atahualpa Yupanqui, simpatizaban con la extrema izquierda y encontraban en algunos valores criollos ecos de los valores revolucionarios (Chamosa 2010).

\section{Las transformaciones de las danzas: el papel de los folklorólogos}

Todas las danzas clasificadas como folklóricas o tradicionales y apropiadas en contextos de construcción de estados nacionales, han pasado por un proceso de re contextualización: es decir, son formas originarias de un tiempo y espacio determinados que se documentan con el fin de ser presentadas en otro momento y lugar. Los llamados "renacimientos" (revivals), por ejemplo, pasan por diversos procesos: la re-gentrificación o apropiación de prácticas de otras comunidades; la reconstrucción o alteración de elementos de repertorio y coreografía; la re-denominación o cambio de nombre; la re-situación o cambio del contexto de la performance, por ejemplo del ritual al escenario; y la restauración o unión de dos prácticas antiguas, para conformar una "nueva práctica antigua" (Allen en Reed 1995:508). Otras transformaciones comprenden la fosilización o reducción de variaciones en la performance; la

\footnotetext{
${ }^{5}$ En su reciente libro, Oscar Chamosa (2010) se detiene en el rol "posibilitador" que las élites regionales tuvieron para el desarrollo inmediato de la ciencia del folklore. La diferencia radica en que Blache evalúa su actividad en sus efectos a largo plazo.
} 
festivización u orientación hacia la presentación escénica que separa audiencia de artistas; y la anticuarización o desplazamiento de los referentes hacia épocas pretéritas. La descripción de estas transformaciones es usada por los investigadores para sostener que con el objetivo de preservar al folklore, los estados nacionales descontextualizan los comportamientos expresivos de determinados grupos, los sanitarizan ideológicamente y los convierten en entretenimiento para audiencias urbanas pasivas (Maners 2006:80-81).

Pablo Parga (2004) en su libro Cuerpo vestido de nación. Danza folclórica y nacionalismo mexicano (1921-1939) describe la academización de las danzas floklóricas mexicanas a partir de 1920. Encuentra que este proceso de institucionalización, impulsado desde establecimientos estatales, permeó la actividad artística y folklórica nacional creando un "deber ser" acartonado y rígido, vacío de contenido y expresividad popular.

En todas estas transformaciones, los miembros de la academia - ya sean del folklore, la etnología o la musicología - han tenido un rol fundamental. En Perú, por ejemplo, los intelectuales participaron tanto de iniciativas estatales como privadas, basadas en el folklore para representar la nación. José María Arguedas, por entonces estudiante de etnología, estaba encargado de monitorear la autenticidad de las enseñanzas impartidas en cursos de danzas organizados por el gobierno desde 1945. En este caso, la autenticidad había sido definida en función de la fidelidad con las prácticas regionales contemporáneas (Feldman 2006: 27-8). En el ámbito privado, otro intelectual - folklorista, José Durand, fundó en 1950 la compañía de danza "Pancho Fierro" que desató el interés de la elite criolla en las tradiciones negras del Perú, y de otras compañías que comenzaron a representar el folklore afroperuano. Las representaciones de las compañías se basaron en el trabajo etnográfico realizado por Durand. Si bien en el programa del estreno afirmaba que la estilización estética había sido dejada de lado en función de la autenticidad, este principio se suspendía en algunos casos en los que se recurrió a técnicas de impacto ${ }^{6}$. Si bien fue una empresa privada, Durand contó con el auspicio del gobierno y el patrocinio de empresas privadas, además de la colaboración de reconocidos diseñadores para el vestuario (Feldman 2006: 34). Un último ejemplo, cuando se convirtió al voudu en símbolo nacional haitiano, el estado lo pasó por un tamiz de sanitarización y desacralización, tratando de separar el ritual de la danza y la magia y superstición de otros aspectos del folklore. En 1949, por ejemplo, el estado le encomendó al primer bailarín del país organizar un ballet nacional de folklore; cada una de sus presentaciones fue

\footnotetext{
${ }^{6}$ Como las técnicas reconocidas como del teatro negro de Praga: Durand utilizó unas quijadas cubiertas con pintura fluorescente que al ser sostenidas por los artistas vestidos de negro e iluminadas con luz negra, dieran la sensación de que las quijadas "flotaban" y se movían por sí solas.
}

presenciada por etnólogos estatales para supervisar la representación de la identidad haitiana (Ramsey en Reed 1998:512-3).

Al realizar mi investigación junto a un ballet de folklore de una localidad de la Provincia de Buenos Aires a partir de 2004, encontré que una de las formas en las que competían en los certámenes, la tradicional, basaba su performance -elección de coreografía, atuendo y música- en documentos. Muchos de estos documentos, compilados por un jurado de la actualidad ${ }^{7}$, provenían del trabajo realizado por los miembros del folklore académico, aunque muchos otros textos eran anotaciones más o menos sistemáticas de maestros de baile, o miembros del movimiento tradicionalista. Entre los autores vinculados con el folklore académico, Carlos Vega, fundador de la escuela de musicología argentina, hizo la más extensa investigación sobre danzas.

Vega entendía que los tradicionalistas practicaban un apego excesivo por la fidelidad a las tradiciones, considerando que esta actitud "excluyente y agresiva, podría engendrar el hastío público"; en el otro extremo, encontraba el peligro de una "evolución desenfrenada [que] traería el extrañamiento y la desnaturalización". Proponía al conocimiento generado por la ciencia del folklore como intermediario entre ambas posturas, ubicándose a sí mismo como experto para guiar el equilibrio entre las formas fosilizadas de los tradicionalistas y otras más atractivas para el público general: "la evolución, medida y controlada por el conocimiento, puede completar la empresa de unificar los estímulos y generalizar las reacciones de un pueblo formado por los descendientes de cincuenta pueblos del mundo." (Vega, 1983:6). Esta idea recorre su libro Danzas Populares Argentinas (1986[1852]) que reunía una serie de investigaciones sobre el baile, concebido como manual para facilitar la práctica de los bailes populares, pero también como fuente para la consulta de eruditos extranjeros. Al finalizar el prefacio sostenía que con la publicación de sus investigaciones, había servido al país y agradecía el apoyo del Estado.

Además de las transformaciones propias de cualquier apropiación por parte del Estado, de la manifestación de un pueblo o región para identificar a la nación en su totalidad, como los procesos de re-contextualización, re-gentrificación, etc., los escritos de Vega muestran una clara y explícita festivización, en el sentido de orientar la descripción de la danza a su presentación escénica. Su descripción del carnavalito en el citado manual es un claro ejemplo donde deja asentada la eliminación de ciertas figuras. Veamos en este párrafo su explicación de las figuras que elije y de las que excluye:

\footnotetext{
7 Aricó, Héctor. 2004. Danzas Tradicionales Argentinas. Una nueva propuesta. 2 da edición. Bs. As: el autor. Para un análisis de este texto y su contexto de uso ver Hirose, M. Belén. 2007. "Los elementos escénicos en los documentos sobre danzas tradicionales argentinas". Presentado en el I Congreso Regional de Folklore. Río Cuarto. Córdoba. Argentina. Agosto 2007.
} 
En el Carnavalito que presento aquí he excluido varias suertes. La causa general de estas eliminaciones es que la inclusión de todas prolongaría demasiado la duración de la danza. ... Las razones secundarias de la exclusión son diversas: prescindo de la Víbora (en la que una de las dos ruedas rompe su círculo y mete su fila por entre los danzantes de la otra como cosiendo a grandes puntadas) por larga y deslucida; omito la variante de la Rueda (en que enfrentados sectores del círculo se acercan y se alejan), porque casi repite la Rueda que incluimos, sin añadir gran cosa; excluyo la Revuelta (especie de "fideo grueso") por violenta y difícil; elimino, en fin, la Jarrita, los Molinetes y el Espejo, porque el Carnavalito las tomó al Pericón de los tradicionalistas. En cambio he dejado la Canasta, pues, aunque acaso provenga también del Pericón, podría haberle llegado al Carnavalito de la Contradanza o la Cuadrilla, y en este caso tendría gran prestigio de tradición. Además, es la figura de las rondas primitivas. Sobre la Canasta jujeña tenemos algo que añadir. Ante todo, hay varias maneras de hacer el enlace; además, suele repetirse para que enlacen una vez los hombres y otra las mujeres. La forma común de los adultos se hace así: de la Rueda (que en las ordenaciones usuales precede a la Canasta) se desprenden las mujeres y forman su ronda adentro mientras los hombres cierra la suya afuera (nuestro Molino); cuando quedan a la par los compañeros, ellos levantan los brazos (unidas las manos), y los pasan por sobre la cabeza de las mujeres, hacia adelante. (Supongo que se comprenderá por qué hemos eliminado esta forma en una selección para escolares ${ }^{8}$ ). (...) En los salones esta danza no tiene un final rigurosamente predeterminado: concluye cuando los bailarines se cansan. Esto no puede ser un espectáculo" (Vega 1986[1852]: 127-8, paréntesis originales; nuestro énfasis).

Los criterios de selección de ciertas figuras y omisión de otras son básicamente dos: la persistencia de figuras "tradicionales" (y por esto entiende aquel momento en el que no puede rastrear información sobre nuevas incorporaciones) favorecería su inclusión; el espectáculo, sin embargo, aparece como criterio fundamental para omitir muchas figuras. De todas maneras, y debido posiblemente al compromiso científico con el que concebía su profesión, hace explícitos sus recortes, y en esto se diferencia de otros manuales coetáneos que simplemente presentan una versión de la danza. Argumenta inmediatamente que esto se debe a que "si conviene, haga quien pueda una ordenación distinta eliminando las adoptadas y adoptando las eliminadas". A pesar de esta aparente amplitud, acto seguido justifica su selección como conteniendo las "más auténticas figuras tradicionales" y que por ende se trata de una "composición en que se han respetado los elementos sociales y la práctica social. La índole de estas danzas permite a cualquiera, por torpe que sea, idear todas las

\footnotetext{
${ }^{8}$ Mi maestra de primer grado no siguió sus recomendaciones porque, en ocasión de bailar el pericón, recuerdo haber hecho la canasta.
}

figuras que quiera, pero eso no tiene mérito ni gracia" (1986[1852]: 128).

\section{La reproducción y representación de la Nación: enseñanza y actuación}

Como ya hemos visto, el decreto de creación de la Escuela Nacional de Danzas que se promulgó durante los primeros años del gobierno peronista, tenía como objetivo explícito la unificación de criterios para la enseñanza, para lograr una expresión unificada del "espíritu argentino". En diversos sentidos, este período es reconocido como fundamental en la consagración del folklore como expresión popular de la nacionalidad. Sin embargo, la relación entre el folklore académico y la enseñanza de las danzas folklóricas no es lineal sino que está mediada por las luchas por definir el repertorio de danzas nacionales. Si bien prestigiosos folklorólogos como Augusto Raúl Cortazar o Isabel Aretz fueron docentes de la Escuela, la figura de Carlos Vega no fue tan relevante - al menos así aparece en los recuerdos de los primeros graduados con los que tuve oportunidad de conversar. Por su parte, la profesora Liliana Randisi, que también estudia la institucionalización de la licenciatura de Folklore en el IUNA (Instituto Universitario Nacional del Arte), me explicó que en las primeras camadas no se utilizaban textos para la enseñanza, sino que cada profesor transmitía lo que había aprendido de la práctica empírica. Así, la legitimidad no residía en una investigación folklórica que respaldara la procedencia de la danza, sino en los propios maestros en el marco de la institución educativa. También esbozaba como posible explicación las diferencias de criterios que Andrés Beltrame, maestro de Barceló, mantenía con Vega.

El énfasis, antes que en un repertorio basado en las investigaciones folklóricas, estuvo puesto en la difusión de las danzas. Según el testimonio de uno de los primeros egresados -el Prof. Alberto Barrientos- la primera camada contó con 5 divisiones de entre 30 y 40 alumnos, lo cual indica un promedio de 175 alumnos, la mayoría de los cuales ya sabía bailar. En ese sentido, si bien la presentación de Andrés Chazarreta - director artístico y empresario de la compañía de danzas de Santiago del Estero que en 1921 se presentó en el espacio capitalino - pudo ser para la época "un fenómeno aislado, y en algún sentido exótico, en una ciudad cuyo pulso lo dan las canciones de los inmigrantes y el recién consolidado tango-canción" (Pujol 1999:220), sus efectos en los años siguientes no pueden considerarse menores. Algunos miembros de su compañía, por ejemplo, fundaron escuelas de danzas en la ciudad de Buenos Aires y enseñaron a bailar a aquéllos que luego formarían las primeras camadas de la Escuela Nacional de Danzas ${ }^{9}$. Por ello, en el momento de la fundación de la Escuela, ya existía una importante

\footnotetext{
${ }^{9}$ El Prof. Alberto Barrientos, graduado de los primeros años de la Escuela Nacional de Danzas, fue alumno de Enrique Suárez, quien fuera bailarín de Andrés Chazarreta, y daba clases de folklore en la ciudad de Buenos Aires.
} 
demanda para la institucionalización de la enseñanza. El mayor aporte del profesorado nacional, según el relato de los graduados, lo aportaba la materia "Metodología". Esta asignatura proveía a los futuros profesores de una sistematización de los elementos a ser enseñados -más allá de bailar y de los movimientos. Es decir, a la enseñanza de las coreografías se sumaba la historia de las danzas, sus características musicales, y todo lo que favoreciera la comprensión de un baile, y por ende, mejorara su interpretación.

La puesta en marcha de la Escuela Nacional de danzas folklóricas tuvo inmediatos efectos sobre la práctica de las danzas en todo el territorio nacional. El objetivo manifiesto en la ley de formar docentes profesionales que se encargaran de la enseñanza de la práctica de bailes folklóricos, fue acompañado de políticas concretas a nivel local, nacional e internacional. El objetivo de difundir las danzas y darles "nueva vigencia" en los ámbitos populares que aparecía en el decreto de creación de la Escuela Nacional de Danzas, se concretó inmediatamente en una serie de actividades por las cuales las danzas fueron incentivadas en la capital a través de talleres en las escuelas públicas, y llevadas desde la capital a otras partes del país y del mundo. Durante una mesa en el Congreso Latinoamericano de Folklore del MERCOSUR y Jornadas Nacionales de Folklore 2006, organizado por el área Transdepartamental de Folklore del IUNA, el profesor Ignacio Letamendía, uno de los primeros egresados de la Escuela, relataba que en 1952 el Director de Cultura de la Nación convocó a un grupo de graduados para llevar las danzas folklóricas argentinas a algunas provincias y gobernaciones del interior del país. Junto a una colega, les tocó en suerte el extremo sur y, trasladados en aviones de las Fuerzas Armadas, llevaron su repertorio de danzas argentinas a Ushuaia. Las clases se dictaron para niños, adolescentes y adultos residentes en Tierra del Fuego, e incluso algunos jóvenes que se encontraban cursando el servicio militar obligatorio. El evento finalizó con un espectáculo en el cine local (Letamendía en Gómez y Randisi 2006:145). Este ejemplo nos sirve para iluminar la dinámica primero centrípeta y luego centrífuga del proceso de definición del repertorio de danzas. En un primer momento, se creó en la ciudad de Buenos Aires una institución que sistematizó la enseñanza de danzas basadas en bailes del pasado o de las provincias, y comenzó a otorgar títulos habilitantes. En una segunda instancia, esas danzas fueron distribuidas a las distintas regiones del país. De esta manera, a diferencia de otros países donde los bailes ejecutados en cada región son propios del lugar ${ }^{10}$, en Argentina las distintas regiones recibieron la enseñanza y comenzaron a practicar danzas de procedencia diversa. Esto no significó que las danzas perdieran la ligazón con su región original. El carnavalito, por ejemplo, era percibido como del noroeste; sin

\footnotetext{
10 Ver Mendoza 2000 para el caso Peruano, especialmente desde 1920 hasta 1980, cuando las nuevas generaciones comenzaron a incorporar 'bailes folklóricos' de otras regiones, incluso de otros países.
}

embargo, se le sumó el carácter nacional, y por ende, era bailada tanto en la provincia de Jujuy, como en el territorio nacional de Tierra del Fuego.

El interés por mostrar las danzas nacionales también traspasó los límites del país, tanto en festivales artísticos (algunos competitivos) como en empresas de entretenimiento. En 1959 y en 1961 ballets argentinos viajaron a España y obtuvieron importantes reconocimientos. La delegación de 1959, bajo la dirección de la profesora Beatriz Durante, viajó gracias a las gestiones del Ministerio del Interior. En España, participó del 2do Festival de Folklore Hispano-Americano junto a Chile, Perú, Uruguay, Bolivia, Haití, Panamá, Filipinas y algunas regiones de España; la obtención del primer premio les facilitó una gira por España (Letamendía en Gómez y Randisi 2006:146). Dos años después, esta vez dirigidos por Barceló, el Conjunto Folklórico de Universidades Populares Argentinas se presentó en el Festival español donde fueron ganadores del "Primer Premio al Folklore Puro Hispanoamericano". Así, el escenario internacional de la Madre Patria no hacía más que confirmar que las orientaciones oficiales hacia la promoción de sus danzas nativas, eran las adecuadas para celebrar ante chilenos, gallegos, andaluces y peruanos, la esencia corporizada de la argentinidad.

\section{Palabras Finales}

En este artículo hemos recorrido los procesos de apropiación oficial de algunos bailes practicados en el territorio argentino, como transformaciones de las danzas populares regionales, en danzas nacionales. En Argentina, este fenómeno tuvo su punto culminante en el decenio peronista, aunque sus inicios fueron anteriores. Pese al supuesto habitual que atribuye estas transformaciones a la imposición de las políticas culturales del Estado, lo cierto es que varios sectores y actores se dieron cita aquí: miembros del mundo académico y del folklore público, artistas o gestores culturales, políticos y maestros, y los más diversos conjuntos sociales de todo el territorio nacional. Sin embargo, al menos en el caso de las danzas folklóricas convertidas en nacionales, este proceso no comenzó en el interior, de donde abrevaban los eruditos para elaborar manuales, dar clases y extraer inspiración, sino en el centro político nacional y destino por entonces de contingentes ultramarinos y provincianos de inmigrantes. La conversión de danzas populares en danzas folklóricas nacionales tuvo en el sistema público educativo a su principal anclaje y objetivo, y al escenario como su aula. El folklore académico, particularmente mediante la obra de Carlos Vega, participó en este proceso en un período apenas posterior, adecuando los materiales para la función educativo-escénica de la danza nacional.

Ciudad de Buenos Aires, agosto de 2010 


\section{Agradecimientos}

Agradezco a todos los miembros del proyecto Pict 17282006 "Antropología Social e histórica del campo antropológico en la Argentina 1940-1980", por las discusiones generales durante los encuentros académicos y especialmente a Rosana Guber, Gastón Gil y Rolando Silla por los comentarios a mi trabajo. También agradezco a Oscar Chamosa que generosamente me envió una copia de su libro antes que saliera publicado.

\section{Bibliografía}

Archetti, E. 2003. Playing Football and Dancing Tango: Embodying Argentina in Movement, Style and Identity. En Dyck, Noel; Archetti, Eduardo (Ed.). Sport, Dance and Embodied Identities. Oxford, New York: Berg.

Blache, E. 1991. "Folklore y nacionalismo en la Argentina: su vinculación de origen y su desvinculación actual". En Revista de Investigaciones Folklóricas 6 pgs. 56-66.

Buckland, T. J. 2006. Dance History and Ethnograpphy: frameworks, sources, and Identities of Past and Present. In Buckland, Theresa J. (ed.) Dancing from Past to Present. Nation, Culture, Identities. Wisconsin: The University of Wisconsin Press.

Chamosa, O. 2010. The Argentine Folklore Movement. Sugar Elites, Criollo Workers, and the Politics of Cultural Nationalism, 1900-1955. Tucson: The University of Arizona Press.

Degiovanni, F. 2007. Los textos de la patria. Nacionalismo, políticas culturales y canon en Argentina. Rosario: Beatriz Viterbo Editora.

Devoto, F. 2005. Nacionalismo, fascismo y tradicionalismo en la Argentina moderna. Buenos Aires: Siglo XXI.

Feldman, H C. 2006. Black Rhythms of Peru. Reviving the African Musical Heritage in the Black Pacific. Middletown: Wesleyan University Press.

Garramuño, F. 2007. Modernidades primitivas: tango, samba y nación. Buenos Aires: Fondo de Cultura Económica.

Gómez, S y L. Randisi. 2006. "Texto y Contexto: aportes para la comprensión del tiempo histórico y los cambios emergidos en instituciones de arte vinculadas con la enseñanza oficial del Folklore en nuestro país - Primera Parte". En Folklore Latinoamericano. Tomo IX. Buenos Aires: IUNA Folklore.

Guss, D. 2000. The Festive State. Race, Ethnicity and Nationalism as Cultural Performance. Berkeley: University of California Press.
Hughes-Freeland, F. 2006. Construction a Classical Tradition: Javanese Court Dance in Indonesia. In Buckland, Theresa J. (ed.) Dancing from Past to Present. Nation, Culture, Identities. Wisconsin: The University of Wisconsin Press.

Kaeppler, A. 2006. Dances and Dancing in Tonga: Anthropological and Historical Discourses. In Buckland, Theresa J. (ed.) Dancing from Past to Present. Nation, Culture, Identities. Wisconsin: The University of Wisconsin Press.

Manners, L D. 2006. Utopia, Eutopia, and E.U. -topia. Performance and Memory in former Yugoslavia. In Buckland, Theresa J. (ed.) Dancing from Past to Present. Nation, Culture, Identities. Wisconsin: The University of Wisconsin Press.

Martín, A. 2005. "Introducción". En Martín, A. (comp). Folclore en las grandes ciudades. Buenos Aires: Libros del Zorzal.

Martinez, I. L. 2002. Danzas Nacionalistas. The representation of history through folkloric dance in Venezuela. Critique of Anthropology, 22(3). 257-282.

Zoila, M. 2000. Shaping society through dance. Mestizo ritual perfomance in the preuvian Andes. Chicago and London.: The University of Chicago Press.

O'Shea, J. 2006. Dancing through history and Ethnography: Indian Classical Dance and the Performance of the past. In Buckland, Theresa J. (ed.) Dancing from Past to Present. Nation, Culture, Identities. Wisconsin: The University of Wisconsin Press.

Pujol, S. 1999. Historia del Baile. De la milonga a la disco. Buenos Aires: Emecé.

Reed, S. 1998. The Politics and poetics of dance. Annual Review of anthropology, Vol 27, 1998. pp. 503-532.

Rojas, R. 1909. La Restauración Nacionalista. Informe sobre Educación. Buenos Aires: Ministerio de Justicia e Instrucción Pública.

Vega, C. 1981. Apuntes para la historia del movimiento Tradicionalista Argentino. Buenos Aires: Instituto Nacional de Musicología Carlos Vega.

Vega, C. 1986 (1952). Las danzas populares argentinas. Tomo I. Buenos Aires: Instituto de Musicología Carlos Vega.

Wulf, E. 2003. The Irish Body in Motion: Moral Politics, National Identity and Dance. En Dyck, Noel; Archetti, Eduardo (Ed.). Sport, Dance and Embodied Identities. Oxford, New York: Berg. 
Zoila, M. 2000. Shaping society through dance. Mestizo ritual perfomance in the preuvian Andes. Chicago and London: The University of Chicago Press. 